\title{
$0.04+80.120$ Welcome to the March 2015 Issue of the IJTMB
}

Antony Porcino, PhD, HSI, Executive Editor, IJTMB

CARE Research Program, Pediatrics, Faculty of Medicine \& Dentistry, University of Alberta, Alberta, Canada

We are pleased to offer three distinct articles in this issue of the IJTMB covering education, sports therapy, and pain management in opioid-dependent patients. Bauer's education article looks at a massage therapy program developed specifically to address the complexity of integrating massage into a multidisciplinary hospital setting. There are several features I find useful: the description of the organic growth of the use of massage within the facility, along with the barriers and facilitators; how massage therapists and massage therapy students were integrated as part of the development team and testing process; and the encouragement of the development of other similar, rigorous, hospital-based massage programs as an area of work specialization.

Mustafa et al.'s exploration of the effects of Swedish massage on kinesthetic differentiation (the ability to perceive, alter, and apply differing levels of force) is an example of massage research focused on elite athletes. I sometimes wonder about the value of research focused on elite athletes, given that few people would seem to directly benefit - and elite/professional sports falls outside the purview of my interests. While athletes obviously require kinesthetic differentiation, we all use it in the process of many activities of daily living, and changes in our differentiation can have significant effect on our ability to function. The introduction and discussion link kinesthetic differentiation to possible fundamental neuromuscular structures and functions. Mustafa and colleagues remind us that their findings are specific to the population studied yet, because of the utility of the result, I'd like to see more research or guidelines for clinicians clarifying when and how to extrapolate such research to nonathletes — and post-sport athletes. ${ }^{(1)}$

The final article, Wiest et al.'s research on the impact of massage in opioid-dependent patients undergoing substance-use treatment, presents a nuanced view into a complex situation where there is a lot of hope for the use of massage therapy. One result of interest is the finding that those participants seeing themselves as capable of being pain-free were more likely to experience clinically significant change in their pain levels. While classic deductive research tries to minimize such patient-centric effects, these findings provide a reminder that clinical relevance and application matter. The work by Wiest and colleagues echoes the recent trend in valuing and assessing patient relevant outcomes, which is an important, welcome perspective to research.

Enjoy this March issue of the IJTMB.

Antony Porcino, PhD, HSI

Executive Editor, IJTMB.

\section{COPYRIGHT}

Published under the CreativeCommons AttributionNonCommercial-NoDerivs 3.0 License.

\section{REFERENCES}

1. Sorenson SC, Romano R, Azen SP, Schroeder ET, and Salem GJ. Life span exercise among elite intercollegiate student athletes. Sports health: a multidisciplinary approach. 2015;7(1):80-86.

Corresponding author: Antony J. Porcino, BSc, PhD, HIS, CARE Research Program, Pediatrics, Faculty of Medicine \& Dentistry, University of Alberta, 8B16A 11111 Jasper Avenue, Edmonton, Alberta, Canada T5K 0L4

E-mail: eeijtmb@gmail.com 